\title{
The role of property taxes in the financing of local government: Case of Turkey
}

Semra Altingoz *,

Suggested Citation:

Abstract 
1. Introduction

2. A General View To Property Tax 
3. The Features Of Property Tax 
4. Conclusion 
References 
